\title{
Sistem Informasi Administrasi Kesiswaan Di SMA Swasta Nusantara Setia Janji
}

\author{
Belly Yasmihan $^{1^{*}}$, Zulfi Azhar ${ }^{2}$ \\ 1,2 Program Studi Sistem Informasi ,STMIK Royal Kisaran, Indonesia \\ ${ }^{1}$ bellyyasmihan@gmail.com, ${ }^{2}$ zulfi_azhar@yahoo.co.id
}

open

access

Histori Artikel:

Diajukan: 26 September 2021

Disetujui: 29 September 2021

Dipublikasi: 30 September 2021

\section{Kata Kunci:}

Administrasi Kesiswaan;

Data; Layanan; Sistem

Informasi; Siswa.

Digital Transformation

Technology (Digitech) is an

Creative Commons License This

work is licensed under a

Creative Commons Attribution-

NonCommercial 4.0

International (CC BY-NC 4.0).

\begin{abstract}
Abstrak
Administrasi Kesiswaan berperan penting dalam mendukung tertib administrasi dalam lembaga pendidikan. Ketersediaan informasi yang akurat mampu mendukung pengambilan keputusan yang tepat dan cepat pada berbagai hal yang menyangkut siswa. Akurasi ini dapat ditingkatkan dengan membuat sistem yang dapat menstandarkan informasi dalam sistem administrasi kesiswaan yaitu dengan pembuatan Sistem Informasi Administrasi Kesiswaan. SMA Nusantara Setia Janji adalah salah satu sekolah yang menginginkan kemudahan dalam pengolahan data dan laporan. Pelayanan yang dilakukan dengan cara manual bisa diselesaikan dengan program aplikasi yang dapat membantu mempercepat proses dan dapat meningkatkan kualitas layanan untuk menghasilkan laporan yang cepat, akurat, dan lebih efektif dan efisien. Sistem informasi administrasi kesiswaan dirancang untuk mengolah data secara efektif dan efisien, selain untuk mengoptimalkan penggunaan komputer yang ada.
\end{abstract}

\section{PENDAHULUAN}

Saat ini ilmu pengetahuan dan teknologi mengalami perkembangan yang semakin pesat, perubahan yang terjadi baik di bidang teknologi, komunikasi, maupun di bidang informasi. Perubahan-perubahan itu disebabkan karena kemampuan dan potensi teknologi informasi itu sendiri, keterbatasan yang dahulu ada dalam komunikasi yang meliputi waktu dan kecepatan sekarang dapat diatasi dengan berkembangnya ilmu pengetahuan dan teknologi, yang memungkinkan manusia untuk saling berhubungan dan mendapatkan informasi dengan cepat, tepat dan tanpa batas. Teknologi dapat diartikan sebagai alat bantu fisik dan non fisik yang digunakan oleh manusia dalam memenuhi kebutuhan dan pencapaian tujuan dalam hidupnya. Komputer memiliki perangkat keras (hardware) dan perangkat lunak (software). Hampir seluruh aktifitas sehari-hari manusia dipengaruhi oleh komputer, baik dalam hal penyampaian informasi seperti mengirim email, melihat berita, mempersiapkan laporan sampai pembuatan program dan lain sebagainya.

SMA Swasta Nusantara Setia Janji terletak di Jalan Besar Sei Silau Barat Kecamatan Setia Janji Kabupaten Asahan Sumatera Utara. Masa pendidikan di SMA Swasta Nusantara Setia Janji ditempuh dalam waktu tiga tahun pelajaran mulai dari kelas X hingga kelas XII, seperti pada umumnya pendidikan sekolah menegah atas di Indonesia. SMA Swasta Nusantara Setia Janji merupakan salah satu institusi pendidikan yang masih menggunakan sistem manual dalam pengolahan data administrasi kesiswaan. Dengan total enam kelas dan total jumlah siswa 170 orang maka akan banyak ditemukan kendala jika tetap menggunakan sistem yang manual. Dengan sistem komputerisasi diharapkan akan mampu menyajikan informasi dengan teliti dan tepat, sehingga sistem administrasi kesiswaan di SMA Nusantara Setia Janji, diharapkan dapat disajikan lebih efisien dibanding dengan menggunakan sistem yang lama. Sistem Administrasi Kesiswaan merupakan usaha kerjasama yang dilakukan oleh para pendidik agar terlaksananya proses belajar mengajar yang relevan, efektif, efisien, guna tercapainya tujuan pendidikan yang diharapkan.

\section{STUDI LITERATUR}

Suatu rancangan sistem imformasi administrasi untuk meningkatkan efisiensi kerja sehingga kegiatan proses usaha dapat berjalan lancar dan baik, meningkatkan keakuratan dalam pengolahan data dan kemampuan penyediaan informasi yang lebih cepat dan meningkatkan kualitas pelayanan kepada konsumen(Supriatin 2012). Administrasi berarti rangkaian kegiatan atau proses pengendalian cara atau sistem kerja sama sejumlah orang, agar berlangsung efektif dan efisien dalam mewujudkan tujuan bersama(Cv and Berbasis 2014). Pemanfaatan sistem informasi elektronik dapat membantu suatu instansi/perusahaan untuk memudahkan pengguna dalam melakukan pengelolaan data sehingga kegiatan administrasinya dapat berjalan dengan lebih produktif, transparan, tertib, tepat, mudah, akurat, terpadu, aman dan efisien. Hal ini sejalan dengan pergeseran paradigma dari regulasi menghambat (wall regulations) menuju regulasi mendorong (enabling regulation)(Handayani 
2016).

Pada masa sekarang ini, informasi dapat diolah secara teratur, cepat dan tepat. Hal ini biasanya disebut dengan istilah sistem informasi. Dalam dunia usaha sistem informasi merupakan suatu hal yang sangat diperlukan bagi kalangan pegusaha seperti pabrik, toko, pengecer dan lain-lain. Dengan adanya kemajuan ilmu pengetahuan dan teknologi komputer maka banyak orang mulai memanfaatkan teknologi komputer untuk mengembangkan sistem informasi yang bersifat manual menjadi sistem yang terkomputerisasi(Hendry 2015)(Willay, Abriyono, and Gultom 2016)(Syariat and Samsudin 2020)(Rifhal Adriansyah 2020)(Damayanti 2019). Sistem informasi adalah kumpulan komponen- komponen yang saling berhubungan yang mengumpulkan, menyimpan, memproses, dan memberikan informasi yang dapat mendukung pembuatan keputusan, pengawasan , analisis dan koordinasi didalam suatu organisasi(Mauliani et al. 2012)(número 442 2012)(Destiana \& Fajrin 2014).

Pada masa sekarang ini, informasi dapat diolah secara teratur, cepat dan tepat. Hal ini biasanya disebut dengan istilah sistem informasi. Dalam dunia usaha sistem informasi merupakan suatu hal yang sangat diperlukan bagi kalangan pegusaha seperti pabrik, toko, pengecer dan lain-lain. Dengan adanya kemajuan ilmu pengetahuan dan teknologi komputer maka banyak orang mulai memanfaatkan teknologi komputer untuk mengembangkan sistem informasi yang bersifat manual menjadi sistem yang terkomputerisasi(Wahyuningsih, Paryanta, and Winoto 2019).

\section{METODE} yaitu :

Metodologi penelitian ini menggunakan beberapa tahapan untuk melakukan pengumpulan beberapa data

a. Metode pustaka (Method Library)

Mendapatkan data dari referensi buku dan jurnal sebagai landasan teoritis yang menjadi sumber data guna mendukung penelitian dalam pengembangan sistem usulan.

b. Metode Observasi (Method of Observation)

Mengambil data dengan meninjau serta mengumpulkan data di SMA Swasta Nusantara Setia Janji untuk mengetahui data administrasi kesiswaan.

c. Wawancara (Interview)

Pengumpulan data dengan cara mengajukan berbagai pertanyaan kepada pihak sekolah di SMA Swasta Nusantara Setia Janji.

\section{a. Aliran Sistem Informasi Baru}

\section{HASIL}

Adapun aliran sistem informasi administrasi kesiswaan baru pada SMA Nusantara Setia Janji adalah sebagai berikut:

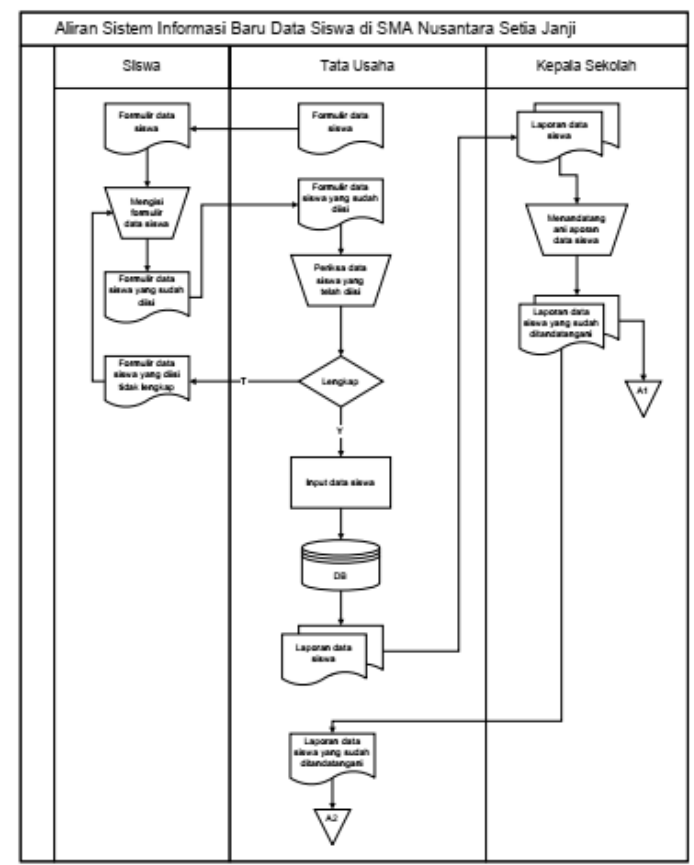

Gambar 1 Aliran Sistem Informasi Baru Data Siswa 
Digital Transformation Technology (Digitech) | e-ISSN : 2807-9000

Volume 1, Number 2, Sep 2021

https://doi.org/10.47709/briliance.v1i2. 1101

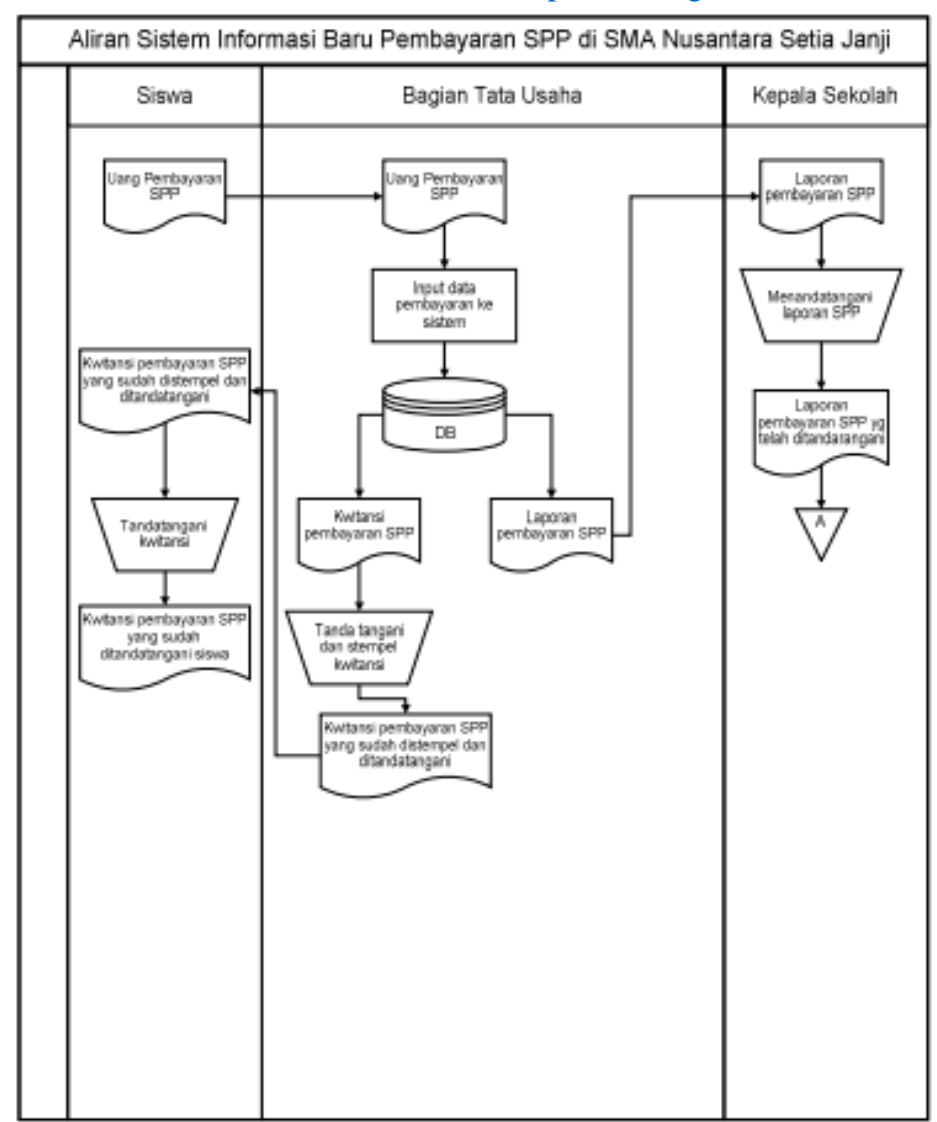

Gambar 2 Aliran Sistem Informasi Baru Transaksi Pembayaran

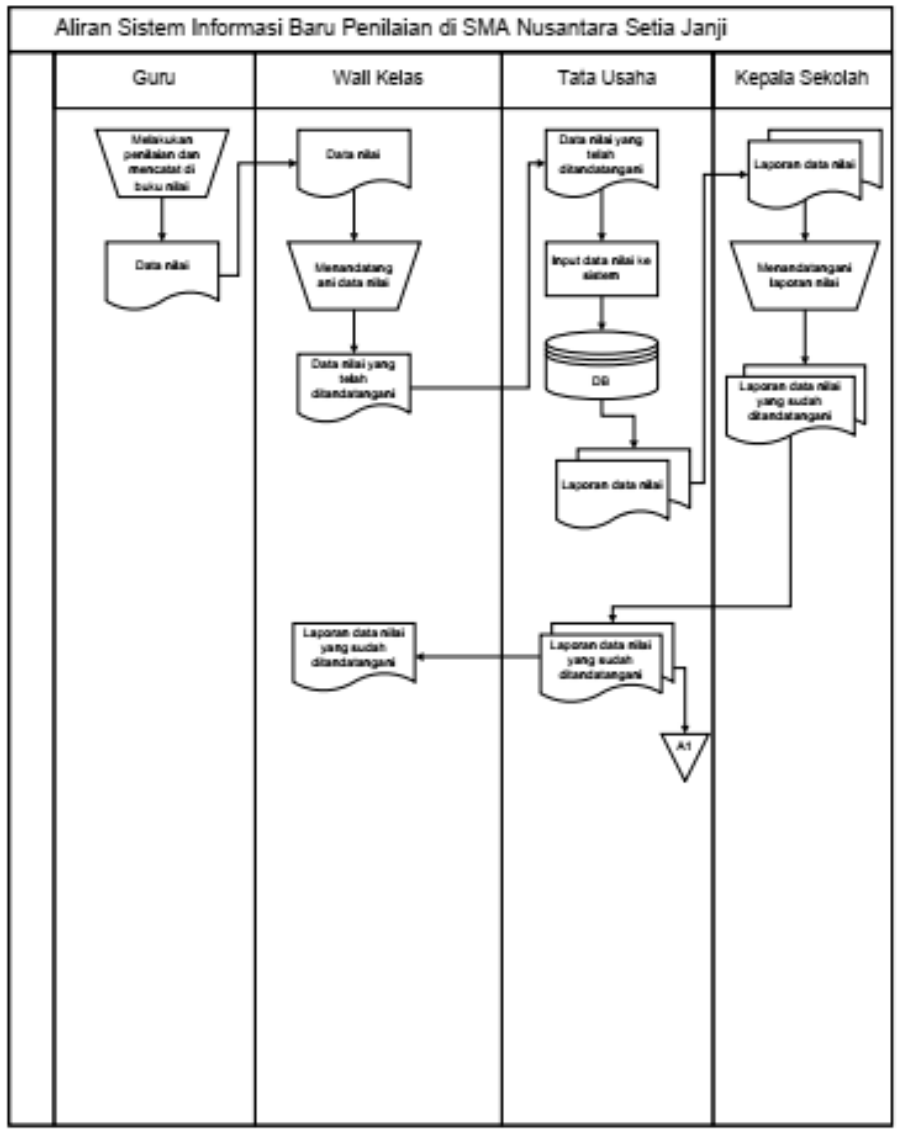

Gambar 3 Aliran Sistem Informasi Baru Penilaian 
https://doi.org/10.47709/briliance.v1i2. 1101 Context Diagram (CD) dari sistem informasi administrasi kesiswaan di SMA Nusantara Setia Janji adalah sebagai berikut:

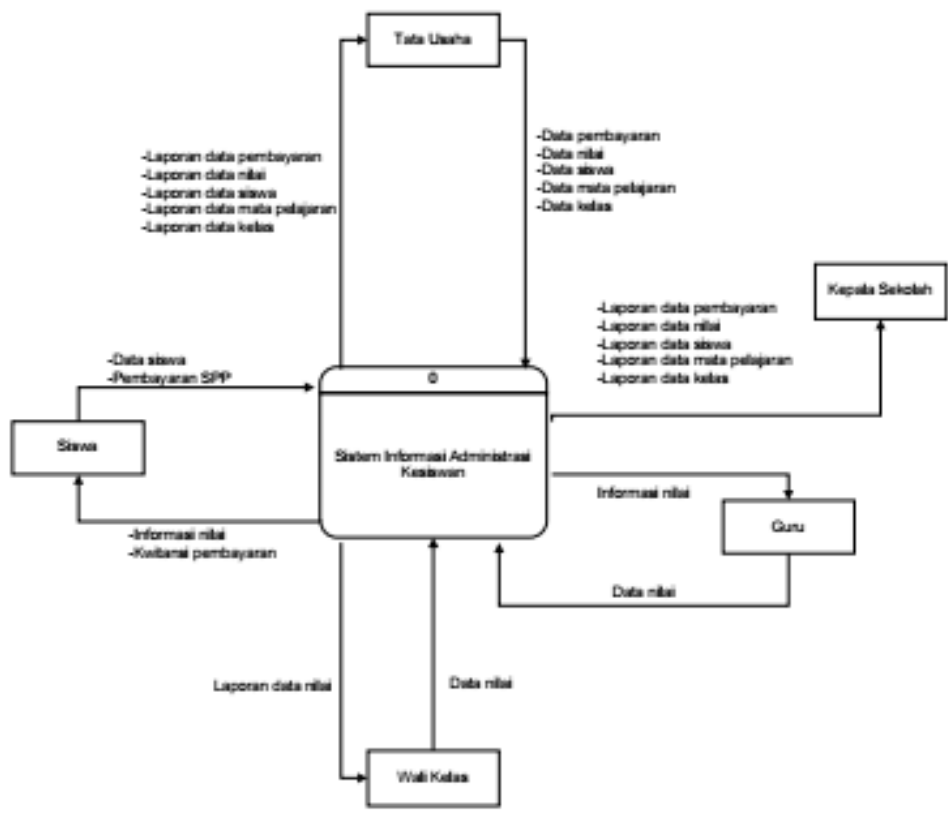

Gambar 4 Context Diagram (CD)

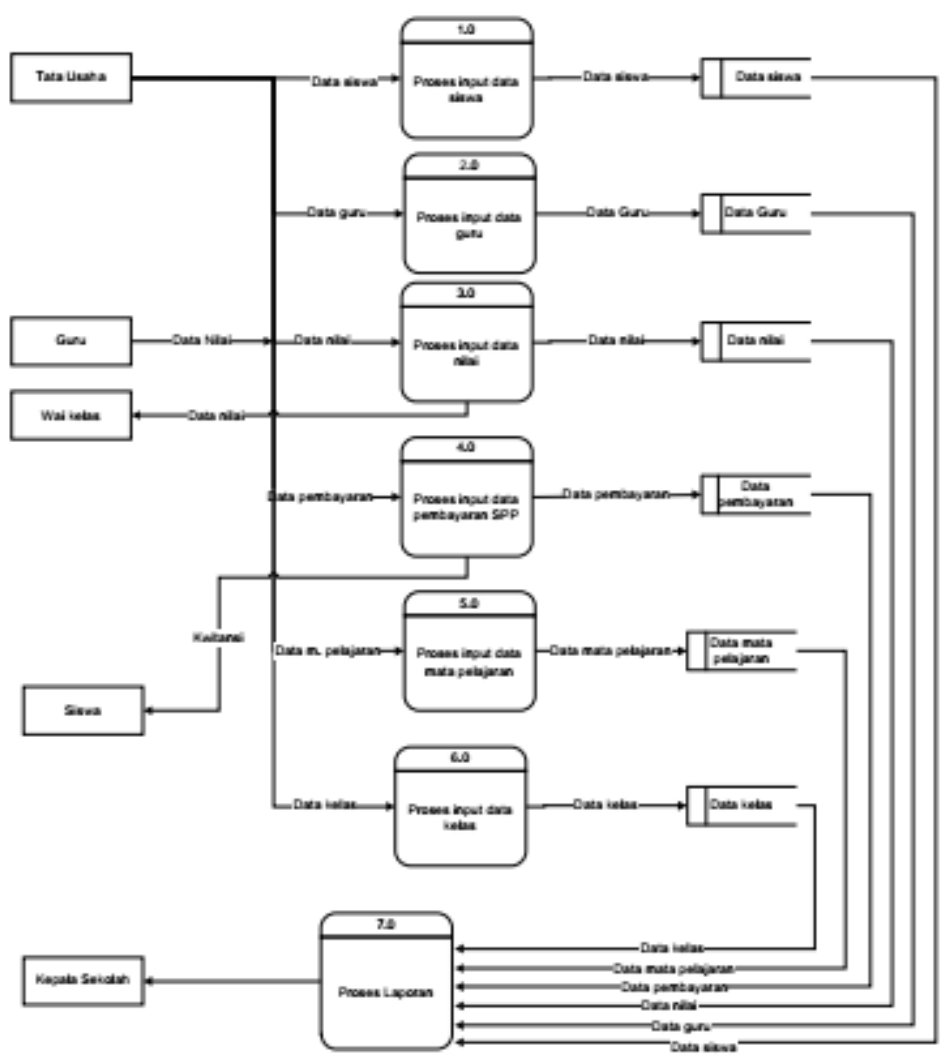

Gambar 5 Data Flow Diagram (DFD) 
Digital Transformation Technology (Digitech) | e-ISSN : 2807-9000

Volume 1, Number 2, Sep 2021

https://doi.org/10.47709/briliance.v1i2. 1101

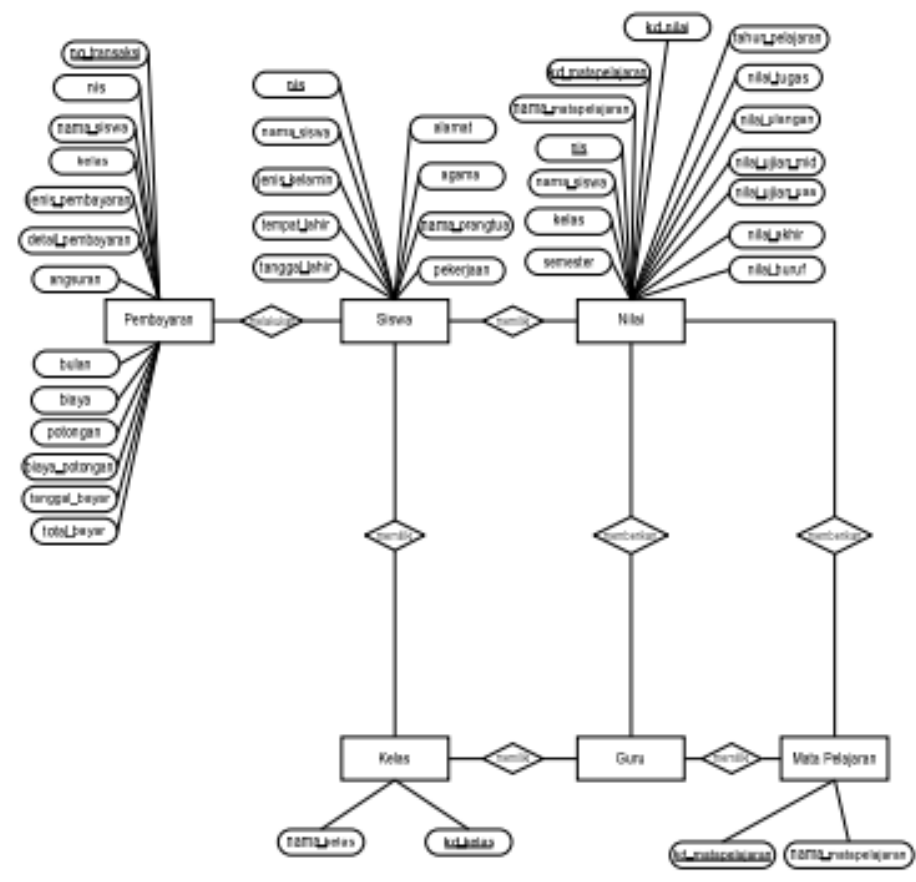

Gambar 6 Entity Relationship Diagram (ERD)

Adapun tampilan rancangan antarmuka pemakai pada sistem informasi administrasi kesiswaan di SMA Nusantara Setia Janji adalah sebagai berikut:

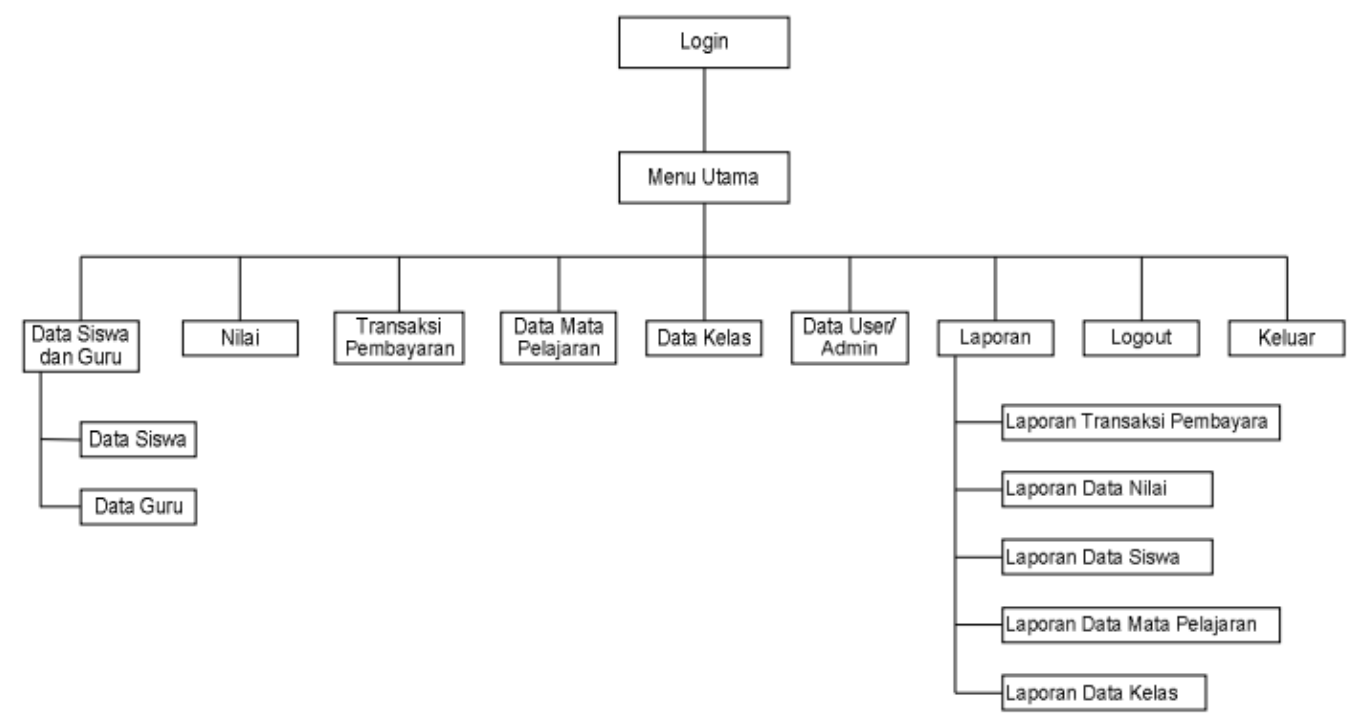

Gambar 7 Tampilan Antarmuka Pemakai 


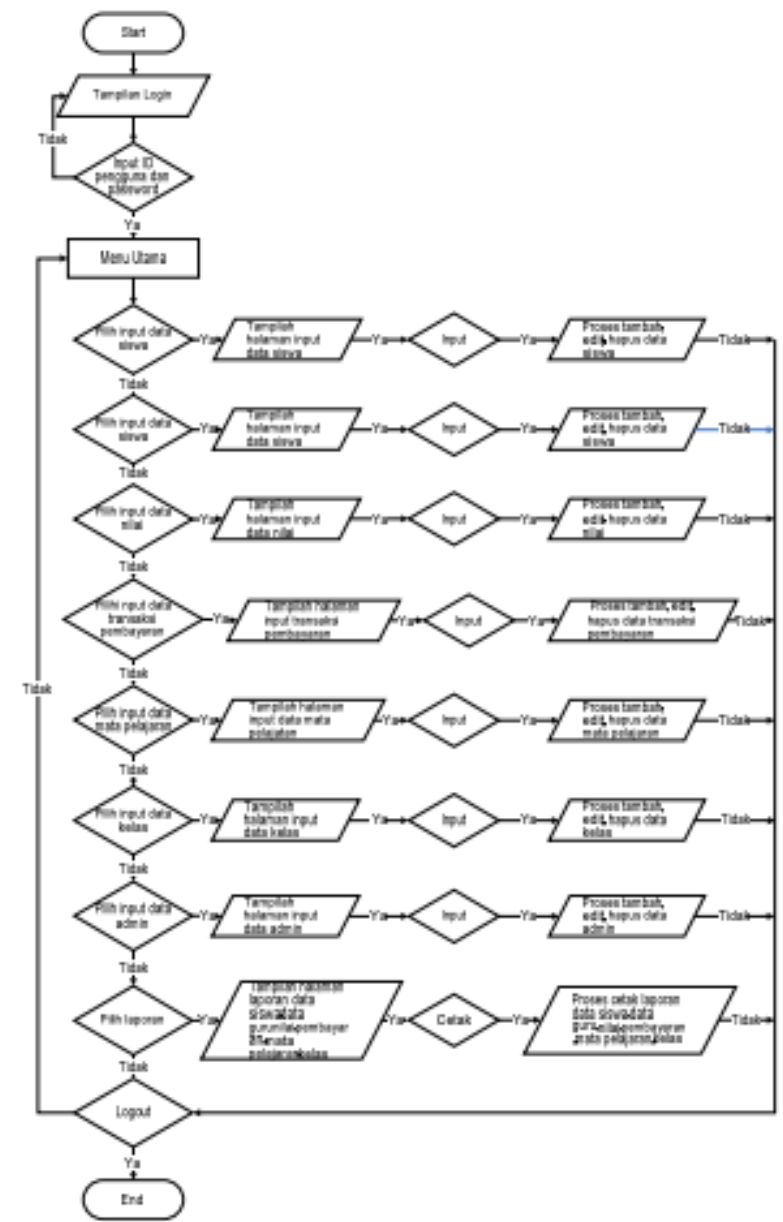

\section{b. Implementasi}

Gambar 8 Flowchart Program

Implementasi adalah tahap penerapan dan sekaligus pengujian bagi sistem berdasarkan hasil analisis dan perancangan yang telah dilakukan dengan implementasi dan pengujian terhadap sistem. Setelah diimplementasikan maka dilakukan pengujian terhadap sistem dan dilihat kekurangan-kekurangan pada aplikasi unuk pengembagan program selanjutnya. Hasil pengujian ini merupakan hasil tampilan program yang telah selesai dibuat. Berikut adalah hasil tampilan program Sistem Informasi Administrasi Kesiswaan di SMA Swasta Nusantara Setia Janji.
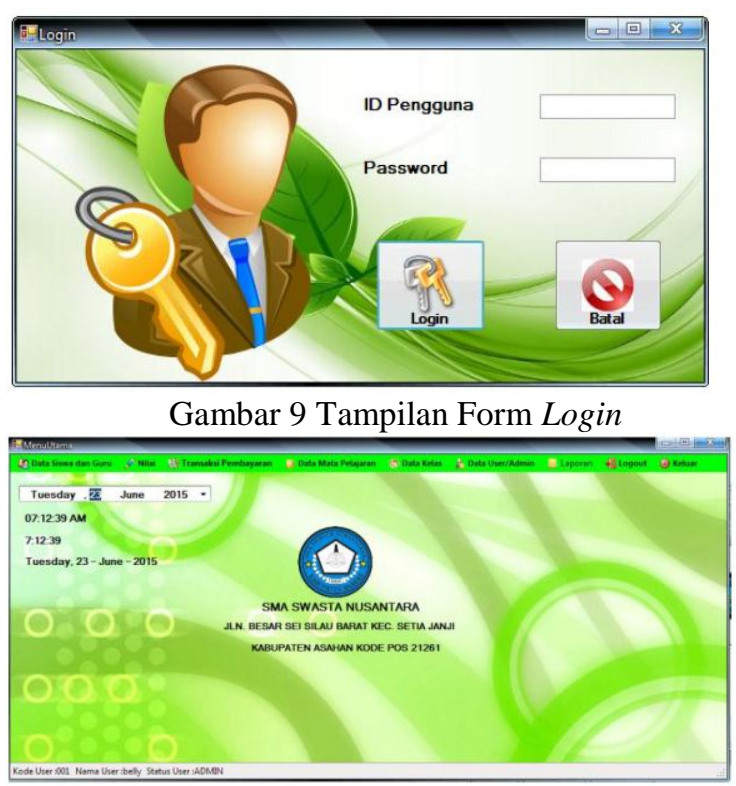

Gambar 10 Tampilan Menu Utama 
Digital Transformation Technology (Digitech) | e-ISSN : 2807-9000

Volume 1, Number 2, Sep 2021

https://doi.org/10.47709/briliance.v1i2. 1101

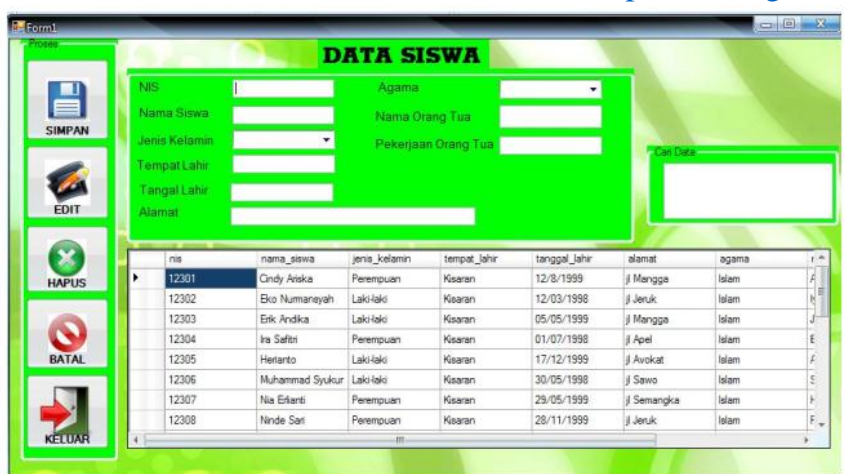

Gambar 11 Tampilan Form Data Siswa

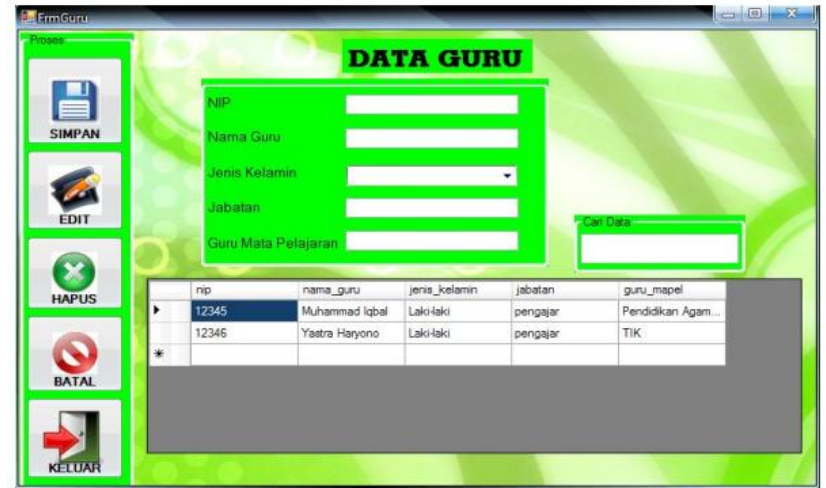

Gambar 12 Tampilan Form Data Guru

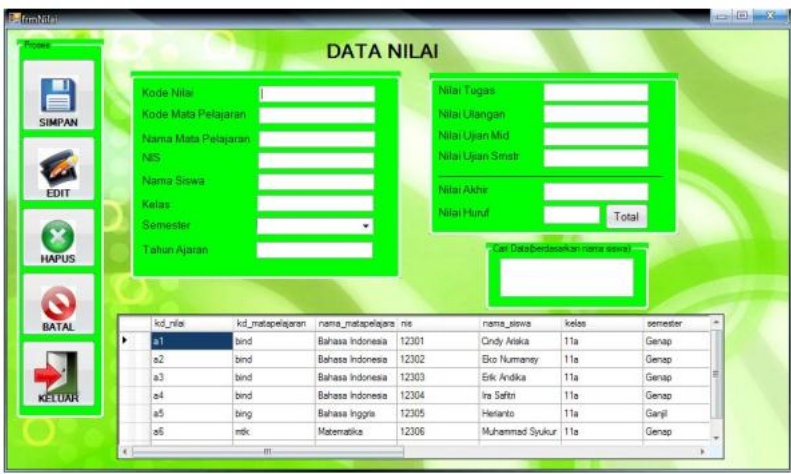

Gambar 13 Tampilan Form Data Nilai

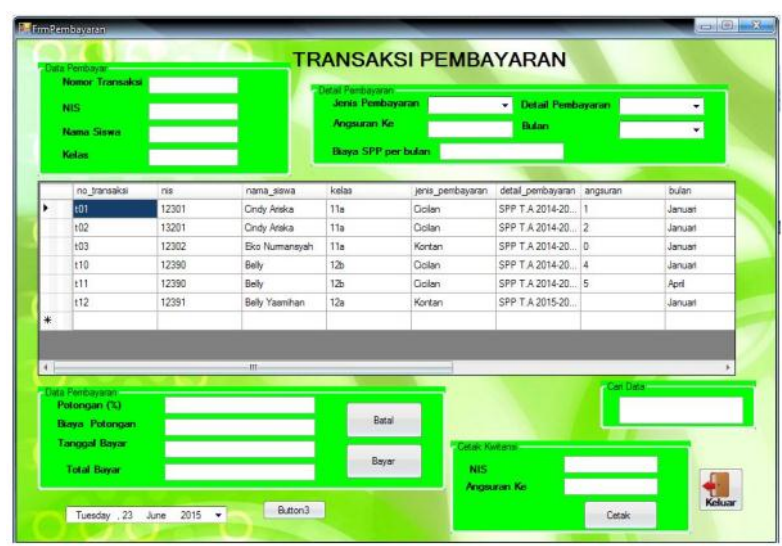

Gambar 14 Tampilan Form Transaksi Pembayaran 
Digital Transformation Technology (Digitech) | e-ISSN : 2807-9000

Volume 1, Number 2, Sep 2021

https://doi.org/10.47709/briliance.v1i2. 1101

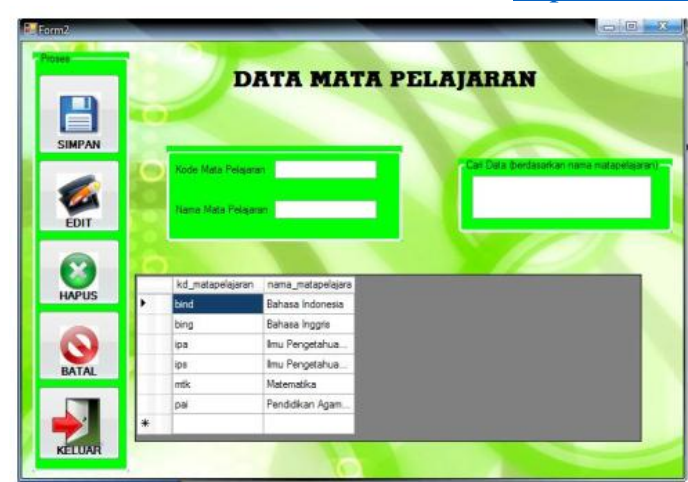

Gambar 15 Tampilan Form Data Mata Pelajaran

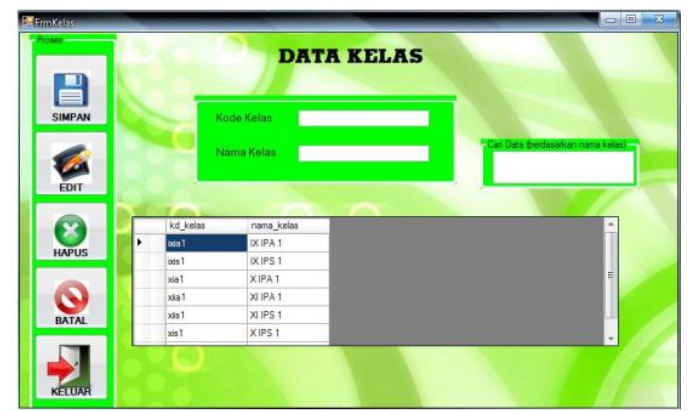

Gambar 16 Tampilan Form Data Kelas
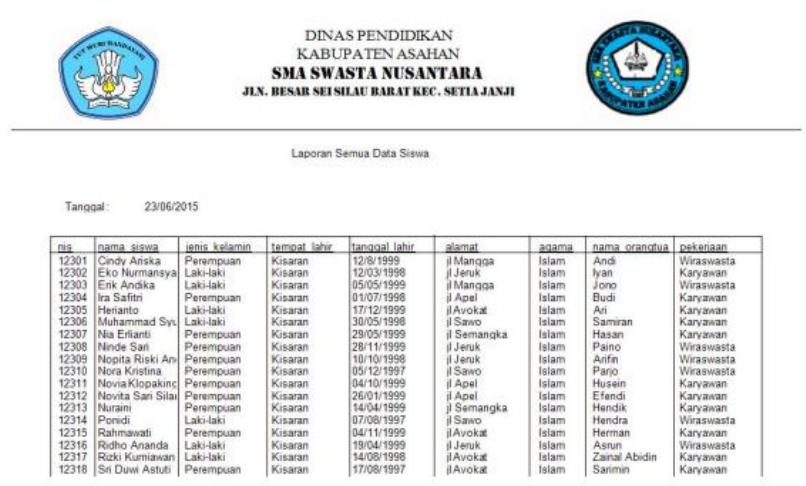

Gambar 17 Tampilan Form Laporan Semua Data Siswa

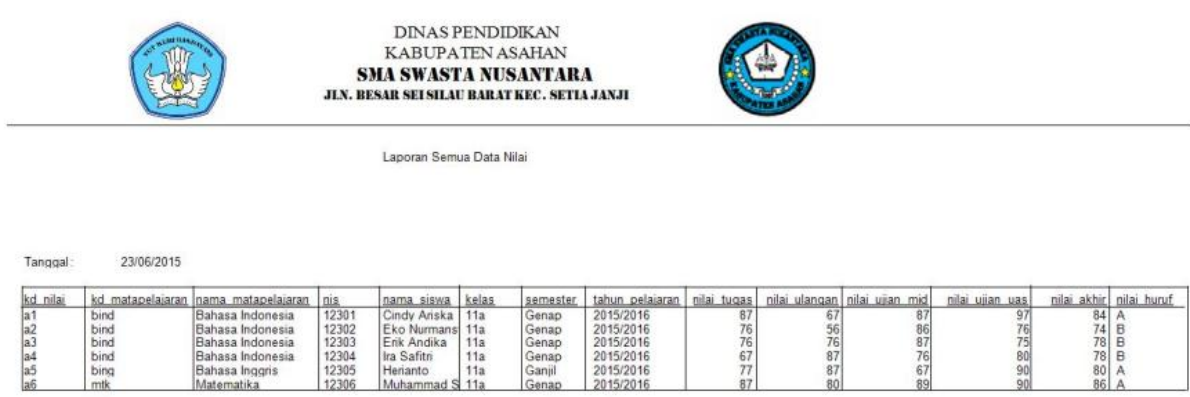

Gambar 18 Tampilan Form Laporan Semua Data Nilai 

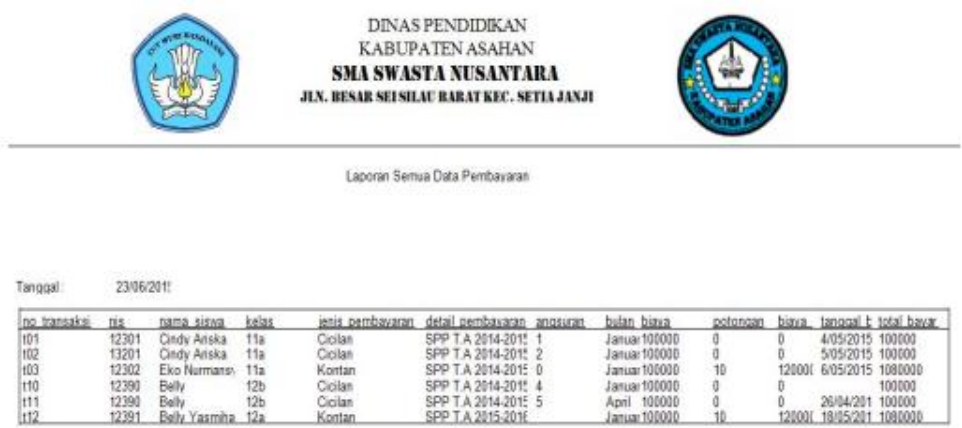

Gambar 19 Tampilan Form Laporan Semua Transaksi Pembayaran

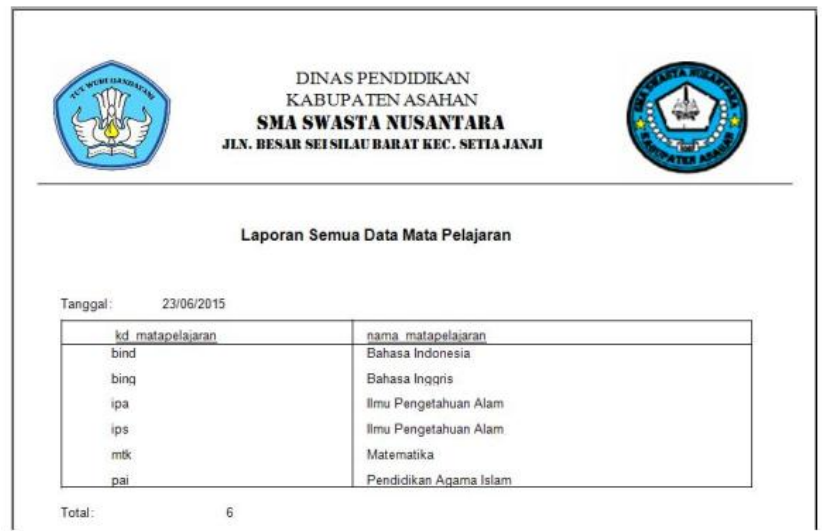

Gambar 20 Tampilan Form Laporan Data Mata Pelajaran

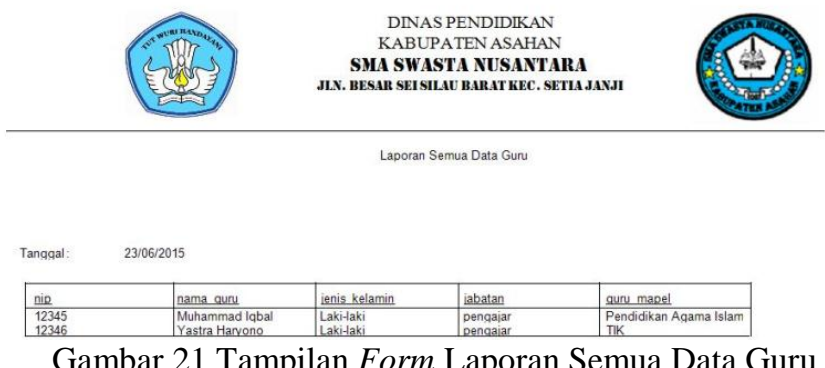

Pengujian yang telah dilakukan merupakan proses yang terdapat dalam Sistem Informasi Adimistrasi Kesiswaan di SMA Swasta Nusantara Setia Janji. Setelah dilakukan pengujian, maka berdasarkan hasil dari pengujian dapat diambil kesimpulan bahwa aplikasi dapat digunakan dengan baik, disamping terdapat beberapa proses lain yang mendukung dalam berjalannya aplikasi ini. Dan semua yang dilakukan dalam pengujian ini diharapkan dapat mewakili pengujian fungsi yang lain dalam Sistem Informasi Adimistrasi Kesiswaan di SMA Swasta Nusantara Setia Janji.

\section{PEMBAHASAN}

Agar sistem ini lebih sempurna diperlukan pengembangan-pengembangan lebih lanjut. Perlunya dikembangkan sistem keamanan, agar sistem yang sudah ada dapat terjaga dari hal-hal yang tidak diinginkan. Tenaga administrasi di SMA Swasta Nusantara Setia Janji harus dilatih tentang keterampilan menggunakan komputer.

\section{KESIMPULAN}

Perancangan Sistem Informasi Administrasi Kesiswaan di SMA Swasta Nusantara Setia Janji merupakan pengembangan dari sistem yang sedang berjalan. Berbagai permasalahan yang muncul telah diupayakan untuk dapat ditangani dengan sistem yang baru. Adapun kesimpulan yang dapat diambil dari perancangan sistem informasi Administrasi Kesiswaan ini antara lain bahwa proses pengolaahan data administrasi kesiswaan pada SMA Swasta Nusantara Setia Janji menjadi lebih cepat dalam penyajian informasi. Sistem Informasi 
Administrasi Kesiswaan di SMA Swasta Nusantara Setia Janji menggunakan bahasa pemrograman Visial Basic 2008 dan menggunakan database Access sehingga lebih mudah dalam melakukan pengolahan data dibandingkan sistem lama yang masih menggunakan Microsoft Excel. Sistem Informasi pencatatan data siswa, penilaian, dan transaksi pembayaran di SMA Nusantara Setia Janji lebih cepat menyajikan laporan data siswa yang efektif dan efisien.

\section{REFERENSI}

Cv, Kepegawaian, and X. Y. Z. Berbasis. 2014. "Perancangan Sistem Informasi Administrasi Kepegawaian Cv. Xyz Berbasis Web.” Jurnal Sistem Informasi Universitas Suryadarma 5(2).

Damayanti, Erni. 2019. "Sistem Informasi Penjualan Obat Pertanian Berbasis Web Pada Toko BUTANI Blora." Walisongo Journal of Information Technology 1(2):161.

Destiana \& Fajrin. 2014. "Sistem Informasi Penjualan Barang Berbasis Web Pada Pt. Catur Daya Persada Jakarta." Paradigma - Jurnal Komputer Dan Informatika 16(2):32-43.

Handayani, Putri Kurnia. 2016. "Sistem Informasi Administrasi Data Kepegawaian Pada Bagian Personalia Pt. Xyz.” Simetris : Jurnal Teknik Mesin, Elektro Dan Ilmu Komputer 7(1):373.

Hendry. 2015. "Perancangan Sistem Informasi Penjualan Pada Toko Casio Elektronik." Jurnal Ilmiah Core It (x).

Mauliani, Annisa, Program Studi, Teknik Informatika, Fakultas Komunikasi, D. A. N. Informatika, and Universitas Muhammadiyah Surakarta. 2012. "Sistem Informasi Penjualan Retail."

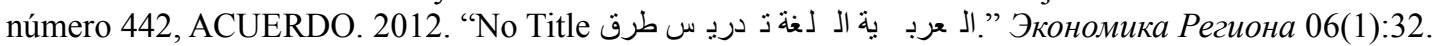

Rifhal Adriansyah. 2020. "Perancangan Sistem Informasi Penjualan Pada Toko Udin Makasar." Jurnal Fasilkom 10(3):277-81.

Supriatin. 2012. “Analisis Dan Perancangan Sistem Informasi Administrasi Kependudukan.” 2(2):12-19.

Syariat, M., and Samsudin. 2020. "Sistem Informasi Penjualan Pada Toko Faisal Elektronik 2 Indragiri Hilir Berbasis Web.” Jurnal Perangkat Lunak 2(1):51-62.

Wahyuningsih, Hartati Dyah, Paryanta Paryanta, and Hetri Candra Winoto. 2019. "Sistem Informasi Penjualan Barang Pada Toko Candra Berbasis Android." Go Infotech: Jurnal Ilmiah STMIK AUB 25(1):11.

Willay, Thommy, Abriyono, and Manorang Gultom. 2016. "Perancangan Sistem Informasi Penjualan (Studi Kasus Pada Toko Apollo).” Jurnal InTekSis Vol 3 No 2 3(2):39-48. 